\title{
Innovations to reduce demand and crowding in emergency care; a review study
}

Suzanne Mason ${ }^{1}$, Gail Mountain², Janette Turner ${ }^{3}$, Mubashir Arain $^{4^{*}}$, Eric Revue ${ }^{5}$ and Ellen J Weber ${ }^{6}$

\begin{abstract}
Emergency Department demand continues to rise in almost all high-income countries, including those with universal coverage and a strong primary care network. Many of these countries have been experimenting with innovative methods to stem demand for acute care, while at the same time providing much needed services that can prevent Emergency Department attendance and later hospital admissions. A large proportion of patients comprise of those with minor illnesses that could potentially be seen by a health care provider in a primary care setting. The increasing number of visits to Emergency Departments not only causes delay in urgent care provision but also increases the overall cost. In the UK, the National Health Service (NHS) has made a number of efforts to strengthen primary healthcare services to increase accessibility to healthcare as well as address patients' needs by introducing new urgent care services.

In this review, we describe efforts that have been ongoing in the UK and France for over a decade as well as specific programs to target the rising needs of emergency care in both England and France. Like many such programs, there have been successes, failures and unintended consequences. Thus, the urgent care system of other high-income countries can learn from these experiments.
\end{abstract}

Keywords: Emergency care, Emergency department, Alternative services, Patient care, Accident and emergency, Health services in England, Walk-in centres

\section{Introduction}

Emergency Department (ED) visits are rising worldwide [1] and many countries are experimenting with novel methods for addressing the demand. Additionally, all health care systems are anticipating greater demand on services with the aging of the population. Despite a very strong network of general practitioners and universal health care coverage, the UK is continuing to see a rise in demand for ED services and increasingly overcrowded departments [1]. The National Health Service (NHS) is responsible for providing healthcare services in the UK and for implementing new services and healthcare related policies. Over a decade ago, the NHS and medical researchers began to address this issue by creating a variety of programs with the goal of not only reducing ED visits and costs but with the intent of more closely matching services to patient needs and preferences [2].

\footnotetext{
* Correspondence: marain@ucalgary.ca

${ }^{4}$ Faculty of Nursing, University of Calgary, 2500 University Drive NW, Calgary, AB T2N 1 N4, Canada

Full list of author information is available at the end of the article
}

Before introducing a new or reconfigured healthcare service is important to assess local needs and ensure that the service is valuable and accessible to the local population. In addition, close monitoring and evaluation of new services is also required to measure impact and to maintain the quality of the services and their proper utilization by patients [3].

The issue of crowding in emergency departments has been identified in other countries and some of the measures, similar to the UK urgent care system, have been implemented. In the USA, walk in centres originated as freestanding emergency centres in the early 1970s. In late 1970s and 1980s, they evolved into 'urgent care centres' or 'ambulatory care centres'. By the year 1986, around 3800 walk-in centres were dealing with 53 million patient contacts per year [4]. These centres offer lower per-episode costs than emergency departments. Urgent care centres, therefore, may reduce overall health system spending if patients substitute care at urgent care centres for care at more expensive sites [5]. 
This review provides examples of different interventions that have been implemented in the UK and some of the similar interventions in France to reduce avoidable demand on ED services. The evidence may provide some useful lessons and guidance for the development of urgent care systems in other developed countries.

\section{Methods}

The Medline (Pubmed), CINHAL and Web of Science search engines were searched to identify the peer reviewed literature. In addition, Google Scholar was used for non-indexed articles and "grey" literature. This is a narrative review set out to describe the most widely used and evaluated approaches in England to manage ED demand. The innovations were identified by the authors who were experts in the area, and then the literature was searched to describe existing evidence for their impact as well as unintended consequences. Where similar efforts have been initiated in other high-income countries, these were noted as well. Most of the cited studies are UK based but studies from France were also included where relevant. Keywords used included urgent care services, walk-in centres, emergency care, accident and emergency, alternative services to emergency department, ambulatory care, minor injuries, GP out-ofhour services. As this was a narrative, scoping review no formal quality assessment was done. Most of the studies included were observational studies and surveys. Major studies were non-randomized controlled studies (before and after design and ecological studies), cross-sectional surveys and studies on secondary data (hospital records). In addition, qualitative studies were also included.

\section{Review}

We reviewed some important interventions to reduce patient load on ED such as telephone triage, alternative primary care services, advanced nursing roles, senior doctor at the front door of the ED, emergency care in the home admission assessment units, targets for emergency departments, and interventions to manage elderly emergency care. There is mixed evidence regarding the effectiveness of these interventions; some of them are more effective than others in terms of improving patients' access to services, and reducing patient load on EDs. There are multiple approaches to manage patient load on EDs. Approaches to manage ED load generally fall into one of the following categories: decreasing ED use, improving resources for managing the higher ED demand, improving flow into and out of the hospital to accommodate newly arriving and admitted ED patients, and elderly emergency care.

\section{Decreasing ED use}

\section{National phone advice lines}

In 1998, the National Health Service of England instituted NHS Direct, a national advice line for health concerns [6]. This was a nurse led telephone service with a principal aim of providing easier and faster advice for patients. There was also an underlying expectation that it might help reduce or limit the demand on other parts of the NHS, in particular ambulance services, EDs and general practice urgent care services by providing self care advice or suggesting alternative places of care, including a routine visit to the general practitioner (GP). However, an evaluation of the early NHS Direct pilot sites conducted by the University of Sheffield showed the advice line had little impact on ambulance use or ED visits [7] and although the service subsequently became nationwide there is no evidence that it has had any impact on the demand for ED care and visits have continued to rise. More recently, NHS Direct has been replaced by a new, free to use service, NHS 111 [8]. The rationale for this change was that as options for accessing emergency and urgent care were increasing, the public were still confused about how to access services appropriately. Whilst NHS Direct was primarily an "advice and direct" service, NHS 111 is a "direct and advice" service with greater integration between the telephone triage element and other health care services. So, for example, an ambulance can be dispatched, the call transferred for additional clinical assessment or appointments with services made in a single telephone call. Unlike NHS Direct, NHS 111 uses non-clinical call handlers for the initial call assessment. The objectives of NHS 111 were to improve access by having only two telephone numbers - 999 for emergencies and 111 for urgent requests - thereby increasing public satisfaction and confidence and improving efficiency within the emergency and urgent care system by directing callers to the "right place, first time". An expected benefit was that this would reduce avoidable ambulance journeys, ED attendances as well as emergency admissions [9]. An evaluation of the first 4 pilot sites found there was no significant impact on ED attendances and that, contrary to expectations, there was a significant increase in ambulance responses [9].

\section{Alternative sites for care}

In 2005 there was a national renegotiation of the General Practitioner (GP) contract allowing GPs to opt out of care of their patients on holidays, nights and weekends. The gap in service delivery was filled by a surge in the organisation of alternative sites of care and expansion of allied health professional roles. There has been a proliferation of Walkin centres and Urgent Care Centres, generally nurse-led with some being remotely situated from EDs and others 
being co-located with the ED. GP-led walk-in centres were established in England in 2009 to increase GP accessibility and to decrease minor case attendance at EDs [10].

Despite the increase in the number of alternative services, studies in the UK show no significant impact of alternative services on ED attendances [11,12]. One ecological study conducted to determine the effect of walk-in centres in reducing waiting time in other primary health care services found no benefit of such centres in reducing load on other health care services [13]. Similarly, other studies reported limited evidence to support any decrease in the EM load where nurse led walk-in centres were co-located with EDs [14]. However, one study on a single walk-in centre has shown a significant decline in ED attendances as a result of the opening of the walk-in centre [15]. Patient satisfaction with quality of service is also greater in walk-in centres as a result of easy access and much shorter waiting times when compared to primary care [16]. Furthermore, the services are of standard quality and safety [17].

It is difficult to accurately measure the impact of opening a parallel service on the ED because when a new health care service is established, it creates its own demand for health care along with sharing the load of existing emergency services. Patient load on other services may actually increase if more patients are consulting these services for minor and self-limiting illnesses as a result of easy access [18]. This may lead to an increased load on health care services as well as increased referrals through these centres. There are several other reasons why alternative services may not be able to show the desired impact on ED attendances such as lack of awareness amongst the general public, patients' perceptions about their health problems and lack of encouragement from health care providers to access alternative services [19].

The concept of walk-in centres was introduced in early 80s when the first walk in centre was opened in Canada in 1980 [20]. Canadian walk-in centres are more comparable to UK walk in centres than USA centres. Two features of Canadian centres are similar to the UK walk in centres. First, they are also funded by general taxation. Second, GPs play a gate keeper role for secondary and tertiary healthcare. A third feature which is similar to the UK is that patients are not charged for using the walk in centres which is different to the USA walk in centres [21].

Australia has recently introduced nurse led walk-in centres (2010) as a result of a shortage of GPs [22]. Australian model is based on the UK urgent care services and similar strategies have been implemented. The centres have been co-located with EDs. Consultations are provided by nurse practitioners only who get support from clinical decision support software. The aim is to complement other healthcare services and reduce patient load at other services [23]. Further evaluations need to be conducted in the future to determine the impact of these services on reducing overcrowding at EDs.

\section{Emergency care in the home}

Paramedic roles have extended substantially with the development in the UK of the paramedic practitioner and the emergency care practitioner. These individuals are trained to assess patients at home and can provide treatment and also referral onwards to other services when appropriate. Training aims to develop skills in history taking, examination techniques and basic investigations (such as urine testing, ECGs, referral for $\mathrm{x}$-ray), and treatment options ranging from referral or signposting to other services, prescription of analgesia or antibiotics and wound management. The focus has generally been on management of minor illnesses and injury conditions, and is often aimed at the management of the frail elderly [24] and therefore incorporates an element of cognitive evaluation and social assessment. Evaluations have shown benefits to patients in reducing the need for onward journeys to the ED, high levels of patient satisfaction, high quality care with no impact on mortality and morbidity demonstrated, and reduced health service costs $[25,26]$.

\section{Technology}

In common with other developed countries, UK health policy is promoting the use of technology as a means of reducing the need for face-to-face contact by health and social care, thereby controlling escalating demands upon services. A new model of health care delivery has been identified which is underpinned by information and communication technologies [27]. Telehealth is one example of such a technology and involves the remote exchange of physiological data such as blood pressure, and other vital signs between the patient and healthcare professionals who are located at a distance [28]. A variety of devices are commercially available which can be used to identify potential deterioration, prevent avoidable hospital admissions and help improve the individual's quality of life [29]. Cited benefits of Telehealth include enabling clinicians to reprioritise their workloads and assisting people with long- term conditions to self-manage [30]. The second main form of technology, Telecare, is concerned with promoting safety and security through monitoring activity in the home and community and providing alerts when that activity falls outside anticipated parameters [31]. The UK policy push for both Telehealth and Telecare has been accompanied by a large ( 5830 subjects at 12 sites), randomised controlled trial of both types of technologies, which demonstrated a mixed picture on outcomes. Patients with COPD, CHF and Diabetes who received tele-monitoring (e.g. glucometer, oxygen saturation, weight monitoring) as well as motivational interventions had fewer emergency visits after adjustment for 
baseline characteristics and predicted risk score (IRR0.85) [32]. Further research in this area is needed to fully understand the possible benefits in terms of cost effectiveness.

\section{Managing demand: expanding capacity without breaking the bank \\ Advanced nursing roles}

Emergency Nurse Practitioners are found among provider staff in most UK emergency departments. Whilst not reducing attendances per se, the evidence has shown that these roles can operate effectively and autonomously in managing a specific workload in the ED mainly relating to minor injury and illness, similar to their roles in many EDs in the USA [33,34]. However, some UK departments have engaged advanced practice nurses for specific streams of protocol-driven care to which patients are directly referred from their GPs, or immediately assigned on arrival to the ED. These include patients with chest pain requiring a "rule-out", often with same-day stress testing, and evaluation and treatment for suspected deep vein thrombosis [35]. There is some concerns that these streamlined services result in more GP referrals to the ED to procure this service, but they also reduce ED waiting times, standardise care and allow predictable follow-ups without physician involvement [34].

\section{Senior doctor at the front door of the ED}

The involvement of senior physicians early in the patient's visit to improve flow is increasingly occurring in the UK. The approach was first recommended by England's Audit Commission in 1999 [36]. Various systems of senior-led initial assessment have been proposed and trialed across the UK already. The 2004 IMPACT study by Terris et al. found that senior physician initial assessment significantly reduced waiting times in the whole department, most especially for 'minors' patients but the effect of additional resources was not directly measured [37]. Team triage by Subash et al. also showed reduced waiting times during the intervention periods but no benefit to the ED beyond these times [38]. Other authors have also observed improved efficiency with senior physician initial assessment; however the process is not thought to be sustainable without additional staffing resources [39-41].

\section{Improving hospital (and therefore ED) flow Admission assessment units}

Most hospitals in the UK now have Medical and Surgical Assessment Units where patients admitted from the ED often go for further assessment by internists or surgeons before being admitted to a specific ward [42]. This decreases the need for extensive testing in the ED, thus reducing ED length of stay and crowding. Increasingly, the
Medical Assessment Units (MAU) are staffed by "Acute Physicians," a growing specialty in the UK. These are senior physicians who have no other responsibilities during their practice day, conduct twice daily patient rounds, and whose primary goal is rapid evaluation of patients. It is expected that more than $50 \%$ of patients admitted to the MAU will be evaluated and discharged within 72 hours; those who cannot be discharged are transferred to specialist wards. Because the MAU's are physically close to the ED's (usually on the same hospital floor), the acute physicians frequently assess patients in the ED and evaluate patients that are likely to need admission, even before the ED has called them. Finally, these units also accept direct admissions from nursing homes and GPs, allowing patients who clearly need admission and who have already been evaluated by a clinician, to bypass the ED.

A study conducted by the Royal College of Physicians in 2012 demonstrated that when these units were staffed appropriately with physicians dedicated to the units that are able to round at least twice daily, the quality of care was higher in terms of reduced case fatality ratio. In addition, a lower 28 day readmission rate was observed. However, they did not demonstrate a shorter length of hospital stay [43].

MAUs have also been established in Australia and New Zealand to reduce pressure on emergency departments [44]. There are various synonyms used by different units throughout Australia and New Zealand and which may be referred to in this document: Acute Medical Ward (AMW) or Unit (AMU), Acute Assessment Unit (AAU), Acute Medical Assessment and Planning Units (AMAPU), and Admission and Planning Unit (APU) [44].

\section{Targets for emergency departments}

In 2002, the UK government introduced a four-hour target, target of arrival in the ED to discharge or admission, for its emergency departments. Initially aimed at $90 \%$ of attending patients, the target quickly rose to include $98 \%$ of attending patients by 2005 . A huge amount of resource and attention was poured into achieving the target, which also received a lot of media attention. Critics point out that this is merely a process measure and does little to improve quality of care. There have been further well-publicised criticisms of the standard; that it leads to 'gaming' and 'cheating' [45]. Other criticisms are that it impairs training and recruitment, reduces professional satisfaction creates an adversarial culture between the emergency department and other inpatient specialties and results in unreliable data. One study found that real-time training opportunities were being lost due to the pressures of the target, and that key skills were not being practiced because they were being referred on to other specialties for management such as complex suturing [46]. However, the pressure that the target brings 
cannot be convincingly and solely linked to the current recruitment difficulties in emergency medicine [46]. The target was reduced to $95 \%$ of patients in June of 2010 after the coalition government was elected. In April of 2011, the target was de-emphasised as it became one of the several indicators in a quality dashboard. Evidence has shown that the target was achievable without compromising on patient care; however, overall performance on the four-hour target has markedly deteriorated since its de-emphasis $[31,46,47]$.

Australia has also been one of the few other countries to embrace the four-hour target concept. However, the Australian picture is more positive, with the introduction of the National Emergency Access Target being associated with a substantial decrease in mortality from $1.12 \%$ to 0.98\% [48]. Similarly, Canada also introduced four-hour emergency department targets in for type $\mathrm{V}$ and type $\mathrm{VI}$ patients [49].

\section{Advancement in elderly emergency care}

The estimates of recent increase in emergency department visits by elderly patients range from 3-6\% annually in the USA, UK, Canada and Australia [50]. Elderly patients have longer length of hospital stays, more complications, and more readmissions [43]. Several programs in the UK are aimed at providing emergency care for the elderly without a visit to the ED, and preventing future visits for those who do arrive. Paramedic Practitioner initiatives described above have been particularly valuable for elderly patients, whose minor conditionscan be treated in the home. A number of hospitals have specific protocols for streamlined management of "elderly fallers" which includes early evaluation in the Emergency Department or the ED's Clinical Decision Unit by teams of staff including physiotherapists, occupational therapists and specialist nurses regarding their ability to be discharged back home. The University Hospital of Leicester established an Emergency Frailty Unit (EFU) where geriatricians perform a comprehensive assessment on elderly patients who are likely to be discharged within 24 hours. Additionally, care pathways were developed for the main ED and physicians in the EFU evaluated patients in that area as well. The assessments of the geriatricians can also be used for direct admissions to skilled nursing facilities, avoiding an inpatient admission. Preliminary data analysis showed that while the numbers of elderly patients attending the ED increased, the likelihood of admission was declined in comparison to historical controls. However, the relative risk for admission was also decreased in individuals under 64 . 90-day readmissions among those over 85 were decreased by $13 \%[51]$.

Of course, England is not alone in recognising the growing impact of the aging populace. France has employed mobile geriatric teams for over a decade; as of 2008, there were 225 such units in the country [52]. The teams, consisting of a geriatrician, nurse and physiotherapist provide geriatric assessments for hospitalised patients and assist with care coordination until the patient is discharged. Moreover, in the ED, they provide assessment and advice for elderly patients. University Hospital, Grenoble has had such a unit since 1997 and is currently trialing the efficacy of home visits to prevent revisits to the hospital within a month of an emergency visit [53].

\section{Conclusion}

New interventions in the delivery of health care have been tried in the UK and France to manage patient load on EDs. The evidence to date suggests that some of the interventions presented in this review, such as the establishment of admission assessment units and emergency care in the home, are very useful to manage patients with urgent care needs. On the other hand, interventions such as setting waiting time targets for EDs and telephone advice services may not be very effective.

Some of these interventions, such as emergency frailty units, provide more patient-centered care and also help to meet patients' needs by providing a high quality service. The evidence has shown that alternative sites for urgent care improve patient access to healthcare services. Improving patients' access is particularly important for urgent health problems. However, an unintended consequence of establishing alternative sites for urgent care and some telephone advice services appear to increase demand for medical services, rather than reducing ED visits Moreover, little is known about the costeffectiveness of establishing alternative sites.

Therefore, an important consideration before replicating these interventions would be to know the primary purpose of implementing these interventions and to determine which service would be beneficial for that particular setting. In addition, the long-term impact of introducing these interventions on the emergency care system is also unknown. Thus, a sound evidence-based program evaluation needs to be developed in order to robustly evaluate new innovations.

\section{Abbreviations}

NHS: National health service; GP: General practitioner; ED: Emergency department.

\section{Competing interests}

The authors declare that they have no competing interests.

\section{Authors' contributions}

SM, GM and JT planned the study and contributed to writing the manuscript. MA, ER and EJW contributed in access literature and writing the manuscript. MA, EJW and JT also helped in editing the manuscript. All authors reviewed and approved the final manuscript.

\section{Authors' information}

SM, Professor of Emergency Medicine, School of Health and Related Research, University of Sheffield, UK. GM, Professor of Health Services 
Research (Assisted Living Research), School of Health and Related Research, Sheffield, UK. JT, Senior Research Fellow, School of Health and Related Research, Sheffield, UK. MA, Postdoctoral Fellow, University of Calgary, Alberta, Canada. ER, MD Head of Emergency Department, Louis Pasteur Hospital and Prehospital EMS, Chartres, France. EJW, Professor of Emergency Medicine, University of California, San Francisco, USA

\section{Acknowledgements}

We acknowledge the School of Health and Related Research, University of Sheffield Library to provide access to the reports and articles included in the study.

\section{Author details}

${ }^{1}$ School of Health and Related Research, University of Sheffield, Sheffield, UK. ${ }^{2}$ School of Health and Related Research, Sheffield, UK. ${ }^{3}$ School of Health and Related Research, Sheffield, UK. ${ }^{4}$ Faculty of Nursing, University of Calgary, 2500 University Drive NW, Calgary, AB T2N 1 N4, Canada. ${ }^{5}$ Emergency Department, Louis Pasteur Hospital and Prehospital EMS, Chartres, France. ${ }^{6}$ Emergency Medicine, University of California, San Francisco, USA.

Received: 15 May 2014 Accepted: 3 September 2014 Published online: 11 September 2014

\section{References}

1. Gillam S: Rising hospital admissions. BMJ 2010, 340:275-276.

2. Mason S: Keynote address: United Kingdom experiences of evaluating performance and quality in emergency medicine. Acad Emerg Med 2011 18(12):1234-1238.

3. Dias S, Severo M, Barros H: Determinants of healthcare utilization by immigrants in Portugal. BMC Health Serv Res 2009, 8:207.

4. Hellstern R: The impact of ambulatory care centers on emergency medicine. Emerg Med Clin North Am 1987, 5:103-117.

5. Maybin J: Just walk in—convenient care has arrived. Medicare Patient Management 2007, Available at: http://ww.medicarepatientmanagement.com/ issues/02-04/mpmJA07-ConvenientCareMaybin.pdf (Accessed: 10th June 2014).

6. Calman K: Developing emergency services in the community, The final report. London: NHS Executive; 1997.

7. Munro JF, Nicholl JP, O'Cathain A, Knowles E: Impact of NHS direct on demand for immediate care: observational study. Br Med J 2000, 21:150-153.

8. Department of Health: NHS 111 when it's less urgent than 999. London: Crown; 2011. http://www.connectingforhealth.nhs.uk/systemsandservices/ pathways/news/nhs111intro.pdf (Accessed April 28, 2014)

9. Turner J, O'Cathain A, Knowles E, Nicholl J: Impact of the urgent care telephone service NHS 111 pilot sites: a controlled before and after study. BMJ Open 2013, 3:e003451. doi:10.1136/bmjopen-2013-003451.

10. Arain M, Nicholl J, Campbell M: Patients' experience and satisfaction with GP led walk-in centres in the UK; a cross sectional study. BMC Health Serv Res 2013, 13(1):142.

11. Chalder M, Sharp D, Moore L, Salisbury C: Impact of NHS walk-in centres on the workload of other local healthcare providers: time series analysis. BMJ 2003, 326(7388):532

12. Penson R, Coleman P, Mason S, Nicholl J: Why do patients with minor or moderate conditions that could be managed in other settings attend the emergency department? Emerg Med J 2012, 29(6):487-491.

13. Maheswaran R, Pearson T, Munro J, Jiwa M, Campbell MJ, Nicholl J: Impact of NHS walk-in centres on primary care access times: ecological study. BMJ 2007, 334(7598):838.

14. Salisbury C, Hollinghurst S, Montgomery A, Cooke M, Munro J, Sharp D, Chalder M: The impact of co-located NHS walk-in centres on emergency departments. Emerg Med J 2007, 24(4):265-269.

15. Arain M, Campbell M, Nicholl J: Impact of a GP led walk-in centre on NHS emergency departments. Emerg Med J 2014, http://emj.bmj.com/content/ early/2014/01/09/emermed-2013-202410.abstract (Accessed May 01, 2014).

16. Salisbury C, Manku-Cott T, Moore L, Chalder M, Sharp D: Questionnaire survey of users of NHS walk-in centres: observational study. $\mathrm{Br} J \mathrm{Gen}$ Pract 2002, 52(480):554-560.

17. Grant C, Nicholas R, Moore L, Salisbury C: An observational study comparing quality of care in walk-in centres with general practice and NHS direct using standardised patients. BMJ 2002, 324(7353):155.
18. Munro J, Sampson F, Nicholl J: The impact of NHS direct on the demand for out-of-hours primary and emergency care. Br J Gen Pract 2005, 55(519):790-792

19. Pope C, Chalder M, Moore L, Salisbury C: What do other local providers think of NHS walk-in centres? Results of a postal survey. Public Health 2005, 119(1):39-44.

20. Hutchison B: The place of walk-in clinics in healthcare systems. BMJ 2000, 321:909-910.

21. Mountford L, Rosen R: NHS walk in centres in London, an initial assessment. King's fund publishing. 2001, Available at: http://www.kingsfund.org.uk/sites/ files/kf/field/field_publication_file/nhs-walk-in-centres-london-inital-assessmentlesley-mountford-rebecca-rosen-kings-fund-1-october-2001.pdf [Accessed: 26 June 2014]

22. Parker R, Desborough J, Forrest L: Stakeholder perceptions of a nurse led walk-in centre. BMC Health Serv Res 2012, 12:382.

23. Desborough J, Parker R, Forrest L: Development and implementation of a nurse-led walk-in centre: evidence lost in translation? J Health Serv Res Policy 2013, 18(3):174-178.

24. Darnell G, Mason SM, Snooks H: Elderly falls: a national survey of UK ambulance services. Emerg Med J 2012, 29(12):1009-1010.

25. Mason S, Knowles E, Colwell B, Dixon S, Wardrope J, Gorringe R, Snooks H, Perrin J, Nicholl J: Effectiveness of paramedic practitioners in attending 999 calls from elderly people in the community: cluster randomised controlled trial. BMJ 2007, 335(7626):919.

26. Mason S, O'Keeffe C, Knowles E, Bradburn M, Campbell M, Coleman P, Stride C, O'Hara R, Rick J, Patterson M: A pragmatic quasi-experimental multi-site community intervention trial evaluating the impact of emergency care practitioners in different UK health settings on patient pathways (NEECaP trial). EMJ 2012, 29(1):47-53.

27. European Commission Information Society and Media: ICT for health and i2010; transforming the European healthcare landscape towards a strategy for ICT for health. Luxembourg: 2006. http://www.ictliteracy.info/rf.pdf/ictforhealth-andi2010.pdf (Accessed on September 07, 2014). ISBN 92-894-7060-7.

28. Curry R, Trejo Tinoco M, Wardle D: Telecare: using information and communication technology to support independent loving by older, disabled and vulnerable people. Report to the UK Department of Health. London: 2002. http://www.rehabtool.com/ forum/discussions/ictuk02.pdf (Access on September 07, 2014).

29. Department of Health: Whole systems demonstrators. An overview of Telecare and Telehealth. 2009, http://webarchive.nationalarchives.gov.uk/ 20130107105354/http://www.dh.gov.uk/prod_consum_dh/groups/ dh_digitalassets/documents/digitalasset/dh_100947.pdf Accessed April 6, 2014.

30. Giordano R, Clark M, Goodwin N: Perspectives on Telehealth and telecare: learning from the 12 whole system demonstrator action network (WSDAN) sites. WSD Action Network 2011, http://www.kingsfund.org.uk/sites/files/kf/ Perspectives-telehealth-telecare-wsdan-paper.pdf Accessed April 6, 2014

31. Brownsell S, Bradley D: Assistive technology and telecare. In Forging solutions for independent living. Edited by Porteus J. Bristol: Policy Press; 2003.

32. Steventon A, Bardsley M, Billings J, Dixon J, Doll H, Hirani S, Cartwright M, Rixon L, Knapp M, Henderson C, Rogers A, Fitzpatrick R, Hendy J, Newman S, Whole System Demonstrator Evaluation Team: Effect of telehealth on use of secondary care and mortality: findings from the whole system demonstrator cluster randomised trial. BMJ 2012, 344(3):e3874-e3874.

33. Cole FL, Ramirez E: Nurse practitioner autonomy in a clinical setting. Emerg Nurse 2000, 7:26-30.

34. Carter AJ, Chochinov $\mathrm{AH}$ : A systematic review of the impact of nurse practitioners on cost, quality of care, satisfaction and wait times in the emergency department. CJEM 2007, 9(4):286-295.

35. Cooper S: Leek moorlands hospital nurse-led deep vein thrombosis clinic. 2007. http://www.institute.nhs.uk/quality_and_value/productive_community_ hospital_improvement_stories/leek_moorlands_hospital_nurseled_deep_vein_thrombosis_clinic.html (Accessed April 23, 2014)

36. The Audit Commission for Local Authorities and the National Health Service in England and Wales: By accident or design: improving A\&E services in England 'and Wales. London: HM Stationery Office; 1996. http://archive.auditcommission.gov.uk/auditcommission/subwebs/publications/studies/ studyPDF/1151.pdf (Accessed on May 01, 2014).

37. Terris J, Leman P, O'Connor N, Wood R: Making an impact on ED flow: improving patient processing assisted by consultant at triage. Emerg Med J 2004, 21:537-541.

38. Subash F, Dunn F, McNicholl B, Marlow J: Team triage improves emergency department efficiency. Emerg Med J 2004, 21:542-544.

39. Grant S, Spain D, Green D: Rapid assessment team reduces waiting times. Emergency Medicine 1999, 11(2):72-77. 
40. Redmond $\mathrm{AD}$, Buxton $\mathrm{N}$ : Consultant triage of minors in an $\mathrm{A}$ \& $\mathrm{E}$ dept. Arch Emerg Med 1993, 10:328-330.

41. Bayley MD, Schwartz JS, Shofer FS, Weiner M, Sites FD, Traber KB, Hollander JE: The financial burden of emergency department congestion and hospital crowding for chest pain patients awaiting admission. Ann Emerg Med 2005, 45(2):110-117.

42. Medical assessment unit (MAU), Frimley Park Hospital, NHS Foundation Trust: Url http://www.frimleypark.nhs.uk/services/medical-assessment-unitmau (accessed on July 22 2014).

43. Royal College of Physicians: An evaluation of consultant input into acute medical admissions management in England report of: hospital service patterns versus clinical outcomes in England. 2012. https://www.rcplondon.ac. uk/sites/default/files/an-evaluation-of-consultant-input-into-acute-medicaladmissions-management-in-england-2012.pdf. (Accessed April 30, 2014).

44. Henley J, Bennett C, Williamson J, Scott I, Medical Assessment and Planning Unit: Internal Medicine Society of Australia and New Zealand Standards for Medical Assessment and Planning Units in Public and Private Hospitals. 2006. url http://www.imsanz.org.au/documents/item/413 (accessed on July 22 2014).

45. Mason S, Nicholl J, Locker T: Four hour emergency target. Targers still lead care in emergency departments. BMJ 2010, 341:c3579.

46. Mason S, Weber EJ, Coster J, Freeman J, Locker T: Time patients spend in the emergency department: England's 4-hour rule-a case of hitting the target but missing the point? Ann Emerg Med 2012, 59(5):341-349.

47. Weber EJ, Mason S, Freeman JV, Coster J: Implications of England's fourhour target for quality of care and resource use in the emergency department. Ann Emerg Med 2012, 60(6):699-706.

48. Geelhoed GC, de Klerk NH: Emergency department overcrowding, mortality and the 4-hour rule in Western Australia. Med J Aust 2012, 196:122-126.

49. Bell R, Affleck A, Carew D, Coleman S, Drummond A, Harrison S, Higgins D, Johnson N, Kennedy S, Mazza C, Murray M, Nobble S, Schull M, Stanley K, Stewart $\mathrm{H}$ : Improving access to emergency care: addressing system issues; report of the physician hospital care committee. 2006. url http://www.health. gov.on.ca/en/common/ministry/publications/reports/improving_access/ improving_access.pdf (accessed on 20th July 2014).

50. Lowthian JA, Curtis AJ, Cameron P, Stoelwinder JU, Cooke M, McNeil J: Systematic review of trends in emergency department attendances: an Australian perspective. EMJ 2011, 28(5):373-377.

51. Conroy SP, Ansari K, Williams M, Laithwaite E, Teasdale B, Dawson J, Mason S, Banerjee J: A controlled evaluation of comprehensive geriatric assessment in the emergency department: the 'Emergency Frailty Unit'. Age Ageing 2014, 43(1):109-114.

52. Couturier $P$, Tranchant L, Lanièce I, Morin T, Gromier E, Sala C, LÔ-Strauss B Functioning of mobile geriatric units or a professional interdisciplinary pattern: experience of Grenoble University Hospital (France). Annales de Gérontologie 2008, 1(1):8-16.

53. Provision of a Mobile Geriatric Team Extra-Community Hospital (UMG): Pl: Pascal COUTURIER, PUPH. http://clinicaltrials.gov/ct2/show/NCT01449968 (Accessed April 30, 2014).

doi:10.1186/s13049-014-0055-1

Cite this article as: Mason et al: Innovations to reduce demand and crowding in emergency care; a review study. Scandinavian Journal of Trauma, Resuscitation and Emergency Medicine 2014 22:55.

\section{Submit your next manuscript to BioMed Central and take full advantage of:}

- Convenient online submission

- Thorough peer review

- No space constraints or color figure charges

- Immediate publication on acceptance

- Inclusion in PubMed, CAS, Scopus and Google Scholar

- Research which is freely available for redistribution

Submit your manuscript at www.biomedcentral.com/submit
C Biomed Central 